\title{
Is cranial multi-detector computed tomography imaging valuable for stature estimation in Egyptian population?
}

\author{
Rana Adel ${ }^{1 *}$, Hala Mohamed Ahmed ${ }^{1}$, Osama A. Hassan ${ }^{1}$ and Ehab A. Abdelgawad ${ }^{2}$
}

\begin{abstract}
Background and objectives: Stature estimation is an initial and essential component of any medico-legal investigations. However, it becomes more challenging when only skull remains are available. So, the goal of this study is to assess stature estimation using cranial multi-detector computed tomography (MDCT) images in a sample of the Egyptian population.

Methods: This clinical study was conducted on 150 Egyptian subjects underwent cranium MDCT with age ranged from 21 to 60 years. The measurements used were maximum cranial breadth, minimum frontal breadth, upper facial breadth, bizygomatic breadth, orbital height, orbital breadth, parietal chord, bimastoidale, maximum cranial length, basion-bregma height, cranial base length, and basion-prosthion length.

Results: The results revealed that stature and craniofacial measurements of males were significantly higher than those of females, all measurements were significantly positively correlated with stature in pooled cases, but the correlation coefficient differs in separate sex. Simple linear regression for stature estimation showed that the least standard error of estimate (SEE) values for the regression equations obtained when using bizygomatic breadth in pooled cases $(7.9 \mathrm{~cm})$ and in males only $(5.7 \mathrm{~cm})$, while in females using parietal chord had the least SEE $(6.8 \mathrm{~cm})$. Using multiple and stepwise regression analysis reported lower SEE values than simple linear regression analysis.

Conclusion: On the basis of this study, it is concluded that the cranial measurements obtained from MDCT images have limited utility in stature estimation among Egyptians, but could be used as an alternative method in cases where the best predictors, such as long bones, are not available.
\end{abstract}

Keywords: Stature estimation, Regression equations, Skull, Multi-detector computed tomography, Forensic anthropology

\section{Background}

Forensic investigation is mainly focused on the personal identification of deceased persons, as the identity is critical in legal investigations. To identify an individual, it is necessary to establish a biological profile via the estimation of age, sex, ancestry, and stature, also known as the "big four" parameters of forensic anthropology (Divakar et al. 2015), but the

\footnotetext{
* Correspondence: rana.adel@minia.edu.eg

${ }^{1}$ Forensic Medicine and Toxicology Department, Faculty of Medicine, Minia University, Minya, Egypt

Full list of author information is available at the end of the article
}

task of identification is challenging when decomposed, dismembered, or skeletal remains are recovered (Kanchan et al. 2008), stature estimation is of tremendous interest to anthropologists as it narrows down the forensic investigating process (Kumar et al. 2013).

There are two main methods available for adult stature estimation: "anatomical" and "mathematical" (Raxter et al. 2006). The anatomical method involves the direct reconstruction of stature by measuring and adding together the lengths or heights of a series of contiguous skeletal elements from the skull through the foot; it is considered most applicable and provides 
the best approximation of living stature, while the mathematical method uses regression formulae based on the correlation of individual skeletal elements to living stature (Raxter et al. 2006). Numerous studies have concluded that regression equations derived from intact long bones are accurate as long bones are highly correlated with stature. However, long bones may be unavailable, particularly in cases involving mass disasters or skeletal remains, so it is necessary to investigate the correlations between stature and the other bones (Duyar and Pelin 2003). Mathematical stature estimation is a variable among different populations and body proportions (Krishan et al. 2012). Therefore, different formulae are required for different populations and different body parts or bones (Dayal et al. 2008).

The utilization of radiological imaging especially multi-detector computed tomography (MDCT) imaging in anthropometric studies developed great attention as forensic experts can assess bones from these CT images without removing tissue, even when the subject is not skeletonized leading to a decrease in costs and time required for investigations (Franklin et al. 2016).

In cases where only the head and face are available for analysis, cranium would be of great value for person stature estimation; moreover, craniofacial structures are composed largely of hard tissues that are relatively indestructible and remain for a long period of time (Torimitsu et al. 2016).

However, little is known about the correlation between cranial measurements and stature in the Egyptian population so stature estimation formulae from the cranium are required for Egyptians. The objective of this study is to develop an anthropometric method for stature assessment in a sample of the Egyptian population by using cranium (MDCT) measurements and to drive regression equations for stature estimation.

To the best of our knowledge, it is the first study that developed regression equations for stature estimation in Egyptians from skull measurements.

\section{Materials and methods}

This clinical study was conducted at a radiology department in Minia University Hospital after approval of the ethical committee of Minia University and obtaining written informed consent. Data were reviewed for 150 cases ( 80 males and 70 females) with age ranged from 21 to 60 years. All cases were subjected to head study using MDCT from December 2016 to January 2018. Subjects with skull fractures, head thermal injuries, cranial surgeries, and congenital or acquired anomalies in the craniofacial region were excluded from the study and also when the acquired landmark was obliterated or unclear. Cases with age less than 21 years old were excluded due to marked cessation of growth and complete fusion of long bone epiphysis to diaphysis (Scheuer and Black 2004) and persons more than 60 years old as an age-related decrease in stature becomes apparent (Cline et al. 1989).

\section{Methods}

The stature of cases was measured in centimeters using anthropometry by making the subject stand straight on a horizontal resting plane barefooted with the head in the Frankfort plane, buttocks, and heels pressed against the upright position of the instrument and the palms of the hands turned inwards and the fingers pointing downwards. Then the movable piece was brought to the vertex in the mid-sagittal plane (Numan et al. 2013).

Cranial MDCT examinations were performed using PHILIPS 16 multi-slice CT (Ingenuity Flex TM, Health care, Nederland, BV), examination protocol using $64 \times 0.5-\mathrm{mm}$ section collimation scanner with a gantry rotation speed of $400 \mathrm{~ms} /$ rotation, range of box $450-500$, section thickness $0.80 \mathrm{~mm}$, section time1.60 s, standard pitch factor of 0.641 , reconstruction interval $0.5 \mathrm{~mm}$, and total exposure time $6.949 \mathrm{~s}$. Each scan was obtained with a tube voltage of 120 $\mathrm{kV}$ and $399 \mathrm{mAs}$. Axial cuts were taken on the brain and skull and then reconstructed coronal and sagittal images were generated as well as 3D reformatted images that were used to obtain the acquired measures according to Moore-Jansen et al. (1994) except bimastoidale was described by Howells (1989); the used measurements landmarks were illustrated in Table 1.

Measurements obtained from three-dimensional (3D) coronal plane images are the following:

(A) Maximum cranial breadth (XCB): Distance between euryons (Fig. 1).

(B) Minimum frontal breadth (WFB): Distance between both frontotemporales (f) in the coronal plane (Fig. 1).

(C) Upper facial breadth (fmt-fmt): Distance between the two external points on the frontomalar suture (Fig. 1).

(D) Bizygomatic breadth (BZB): Distance between most lateral points on the zygomatic arches (Fig. 1).

(E) Orbital height $(\mathrm{OBH})$ : Distance between the superior and inferior orbital wall (Fig. 2).

(F) Orbital breadth (OBB): Distance from dacryon (d) to ectoconchion (ec); the greatest width of orbit. The diameter should cut the orbital cavity in almost two equal halves. The left orbit is used for all cases for standardization (Fig. 2). 
Table 1 Measurements landmarks

\begin{tabular}{ll}
\hline Landmark & Description \\
\hline Euryon (e) & The two points on the opposite sides of the cranium that form termini of the lines of greatest cranial breadth \\
Frontotemporale (f) & The point where the temporal line reaches its most antero-medial position on the frontal bone \\
Dacryon (d) & The point of junction of the maxillary bone, lacrimal bone, and frontal bone on the medial border of the orbit \\
Ectoconchion (ec) & The most anterior surface of the lateral border of the orbit \\
Bregma (b) & The intersection of the coronal and sagittal sutures in the midline \\
Lambda (l) & The intersection of the sagittal and lambdoidal sutures in the midline \\
Glabella (g) & $\begin{array}{l}\text { The most forward projecting point in the midline of the forehead at the level of the supra-orbital ridges and } \\
\text { apove the naso-frontal suture }\end{array}$ \\
Basion (ba) & The most posterior point on the cranium \\
Nasion (n) & The midpoint of the anterior margin of the foramen magnum \\
Prosthion (pr) & The intersection of the internasal suture with the nasofrontal suture in the midsagittal plane
\end{tabular}

(J) Parietal chord (PAC): Distance from bregma (b) to lambda (1) (Fig. 3).

(H) Bimastoidale (BMS): Distance between points of the mastoid processes (Fig. 4).

The measurement obtained from lateral $3 \mathrm{D}$ images is as follows:

(I) Maximum cranial length (GOL): Distance between glabella (g) and opisthocranion (Fig. 5).

Measurements obtained from the mid-sagittal plane are the following (Fig. 6):

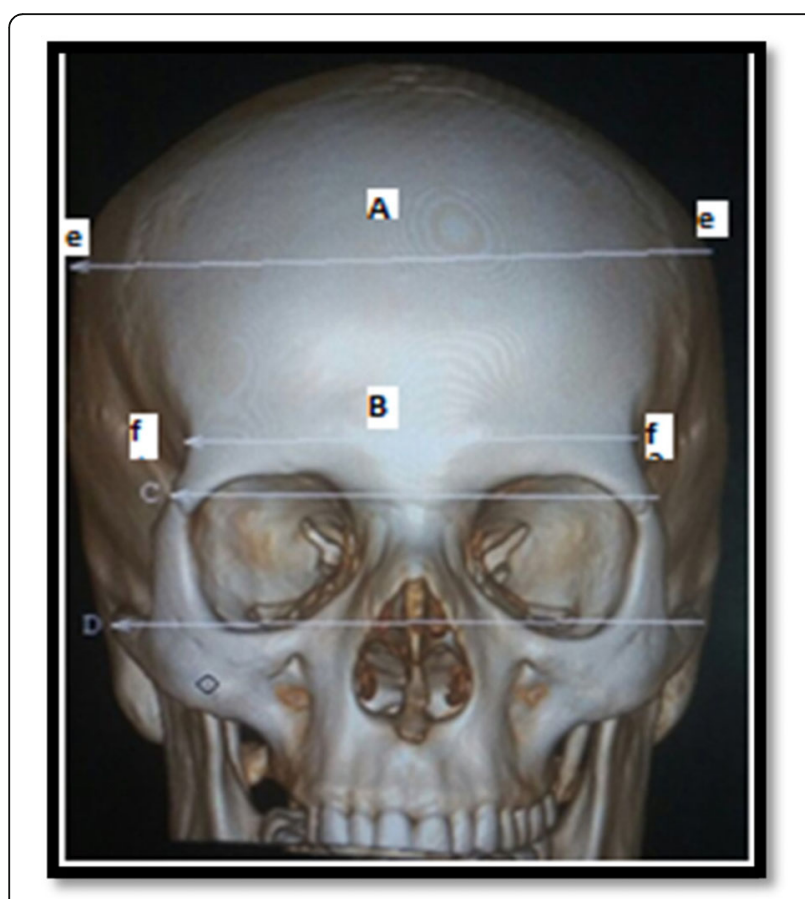

Fig. 1 (A) maximum cranial breadth (XCB), (B) minimum frontal breadth (WFB), (C) upper facial breadth (fmt-fmt), and (D) bizygomatic breadth (ZYB)
(A) Basion-bregma height (BBH): Distance from basion to bregma

(B) Cranial base length (BNL): Distance from basion to nasion

(C) Basion-prosthion length (BPL): Distance from basion to prosthion

The measurements of $10 \mathrm{CT}$ images from randomly selected subjects were performed repeatedly by both the first and fourth co-author to assess inter- and intraobserver error.

\section{Statistical analysis}

The collected data were coded, tabulated, and statistically analyzed using SPSS program (Statistical

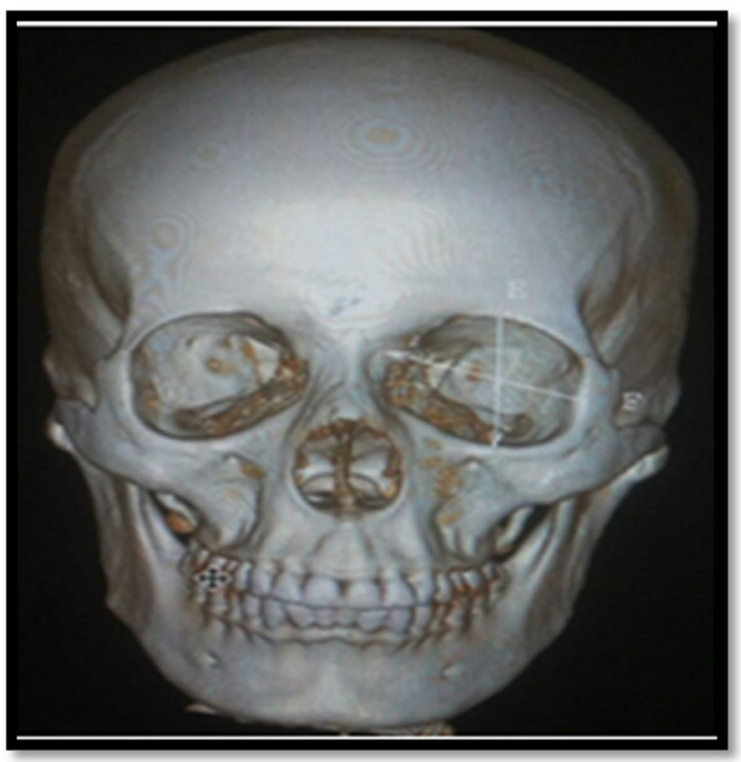

Fig. 2 (E) orbital height $(\mathrm{OBH}),(\mathbf{F})$ orbital breadth $(\mathrm{OBB})$ 


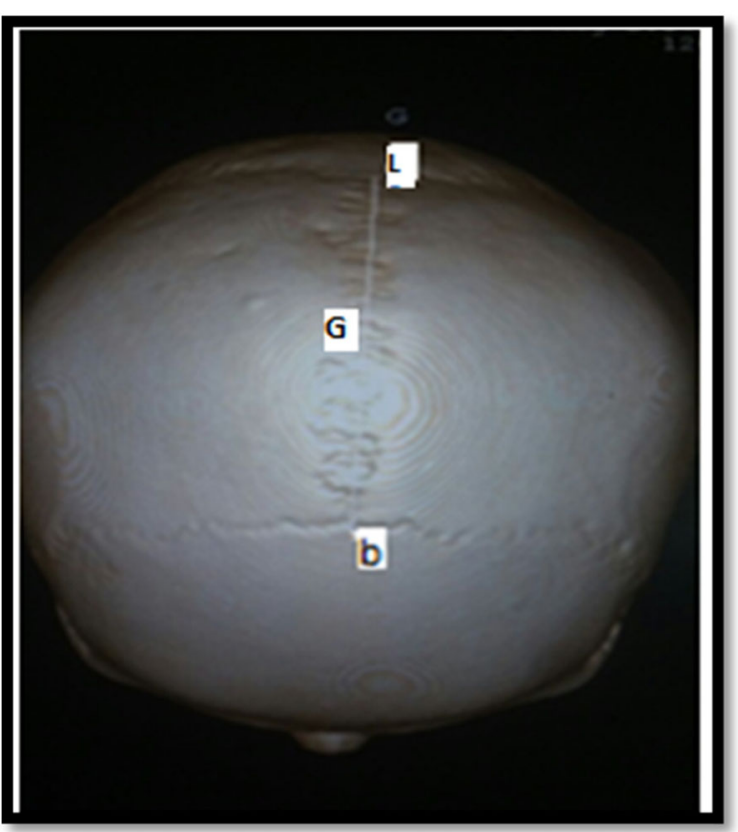

Fig. 3 (G) parietal chord (PAC)

Package for Social Sciences) software version 24. Descriptive statistics were done for numerical data by mean, standard deviation, and minimum and maximum of the range. Analyses were done for parametric quantitative variables between the two groups using independent samples $t$ test. To assess intraand inter-observer errors, the relative technical error of measurement (rTEM \%) and the coefficient of

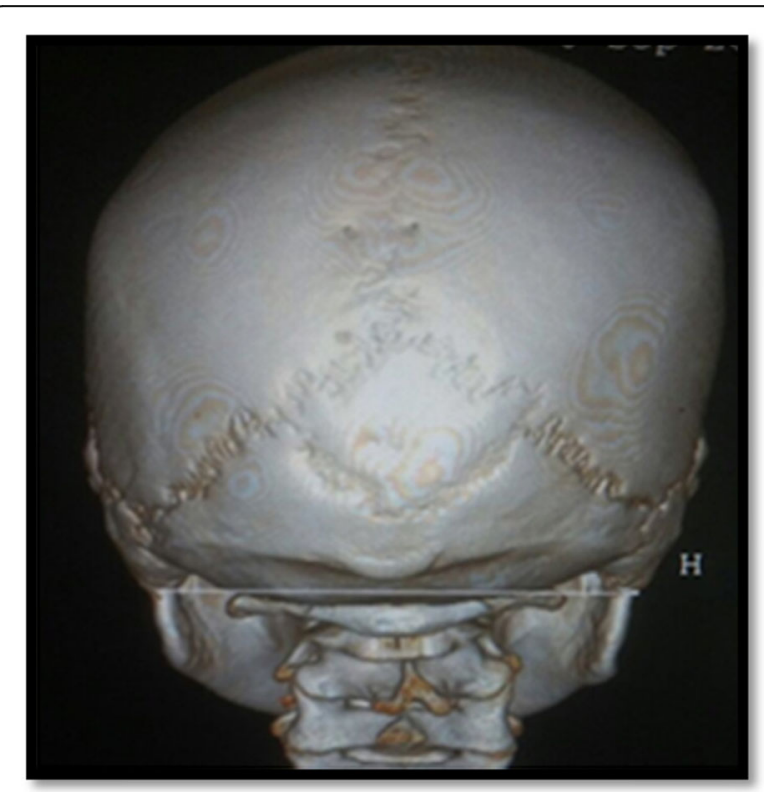

Fig. 4 (H) bimastoidale (BMS)

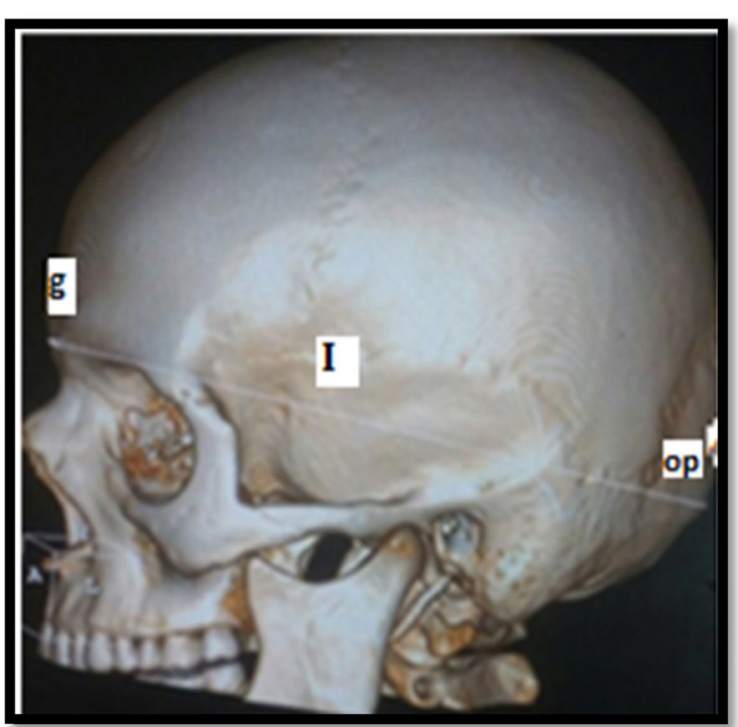

Fig. 5 (I) maximum cranial length (GOL)

reliability $(R)$ were calculated. The acceptance ranges of rTEM in a beginner anthropometrist for intraand inter-observe errors were $<1.5 \%$ and $<2.0 \%$, respectively. An $R$ value, a proportion of the between-subject variance that is free of measurement errors, of $>0.75$ was considered sufficiently precise (Jamaiyah et al. 2010). Correlation between two quantitative variables was done by using Pearson's correlation coefficient. Simple, multiple, and multiple stepwise linear regression analyses were used to determine the equations that predict the person's

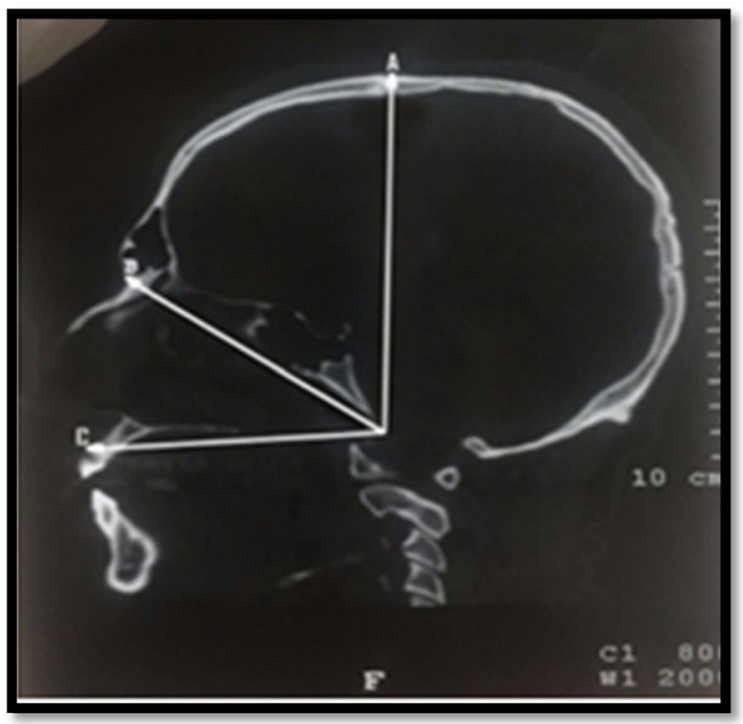

Fig. 6 (A) basion-bregma height (BBH(, (B) cranial base length (BNL), (C) basion-prosthion length (BPL) 
stature using different skull measures, standard error of estimation (SEE, centimeter) was calculated for each formula to evaluate the significance of the regression equations. The adjusted coefficient of determination $\left(R_{\text {adj }}^{2}\right)$ was calculated for multiple and multiple stepwise regression analysis, while the coefficient of determination $\left(R^{2}\right)$ was calculated for simple regression analysis formulae.

\section{Results}

The results revealed that the mean age of tested cases was $38.7 \pm 12.3$ years. The stature of cases ranged from 143 to $184 \mathrm{~cm}$ with a mean of $163.8 \pm 9.5$. The descriptive statistics of different skull measurements among males and females were shown in Table 2, Independent samples $T$ test revealed a significant increase in all skull measurements in males in comparison with females (Table 2). Intra-observer precisions of skull measurements were rTEM $<1.5 \%(0.61-$ $1.07 \%)$ and $R>0.95$ (0.981-0.994); inter-observer precisions were rTEM $<2.0 \%(0.67-1.76 \%)$ and $R>0.95(0.957-$ $0.986)$ as shown in Table 3.

The correlation coefficient between the stature and all skull measurements in pooled cases reported that all skull measurements had significant positive correlation, while in males, $\mathrm{ZYB}, \mathrm{GOL} \mathrm{XCB}, \mathrm{BPL}$, and $\mathrm{OBH}$ measurements showed significant positive correlation with stature, and in females, $\mathrm{XCB}, \mathrm{ZYB}$, OBB, PAC, and GOL measurements showed
Table 3 Intra-observer and inter-observer of relative technical error of measurements (rTEM \%) and coefficient of reliability $(R)$ for all skull measurements ( $n=10$ cases)

\begin{tabular}{|c|c|c|c|c|}
\hline \multirow[t]{2}{*}{ Measurements } & \multicolumn{2}{|c|}{ Intra-observer } & \multicolumn{2}{|c|}{ Inter-observer } \\
\hline & rTEM (\%) & $R$ & rTEM (\%) & $R$ \\
\hline XCB & 0.61 & 0.981 & 0.67 & 0.986 \\
\hline WFB & 0.62 & 0.984 & 1.01 & 0.957 \\
\hline Fmt-fmt & 1.07 & 0.981 & 1.42 & 0.963 \\
\hline ZYB & 0.92 & 0.984 & 1.76 & 0.962 \\
\hline $\mathrm{OBH}$ & 1 & 0.991 & 1.72 & 0.982 \\
\hline OBB & 0.88 & 0.987 & 1.34 & 0.957 \\
\hline PAC & 0.99 & 0.992 & 1.13 & 0.980 \\
\hline BMS & 1.17 & 0.985 & 1.92 & 0.942 \\
\hline GOL & 0.82 & 0.982 & 0.91 & 0.983 \\
\hline $\mathrm{BBH}$ & 0.7 & 0.990 & 1.06 & 0.970 \\
\hline BNL & 0.88 & 0.987 & 1.33 & 0.974 \\
\hline BPL & 0.71 & 0.994 & 1.23 & 0.979 \\
\hline
\end{tabular}

$X C B$ maximum cranial breadth, WFB minimum frontal breadth, fmt-fmt upper facial breadth, $Z Y B$ bizygomatic breadth, $O B H$ orbital height, $O B B$ orbital breadth, $P A C$ parietal chord, BMS bi-mastoidale, GOL maximum cranial length, $B B H$ basion-bregma, $B N L$ cranial base length, $B P L$ basion-prosthion length

significant positive correlation with stature as shown in Table 4.

Tables 5, 6, and 7 showed the results of the simple linear regression equations for stature estimation derived for each of the cranial measurements in pooled cases, males only and females only, respectively. The

Table 2 Descriptive statistics and independent sample $t$ test of stature and skull measurements in pooled cases ( $n=150$ cases), males ( $n=80$ cases), and females ( $n=70$ cases)

\begin{tabular}{|c|c|c|c|c|c|c|c|}
\hline \multirow[t]{2}{*}{ Measurements } & \multicolumn{2}{|l|}{ Mean \pm SD } & \multicolumn{2}{|c|}{ Minimum } & \multicolumn{2}{|c|}{ Maximum } & \multirow{2}{*}{$\begin{array}{l}P \text { value } \\
0.667\end{array}$} \\
\hline & Male & Female & Male & Female & Male & Female & \\
\hline Age & $38.3 \pm 12$ & $39.2 \pm 12.8$ & $21 \mathrm{y}$ & $21 \mathrm{y}$ & $60 y$ & $60 y$ & $<0.001^{*}$ \\
\hline Stature & $169.9 \pm 6.4$ & $156.9 \pm 7.5$ & $153 \mathrm{~cm}$ & $143 \mathrm{~cm}$ & $184 \mathrm{~cm}$ & $175 \mathrm{~cm}$ & $<0.001^{*}$ \\
\hline$X C B$ & $14.4 \pm 1.4$ & $13.3 \pm 1.1$ & $11 \mathrm{~cm}$ & $9.5 \mathrm{~cm}$ & $18.9 \mathrm{~cm}$ & $17.2 \mathrm{~cm}$ & $<0.001^{*}$ \\
\hline WFB & $9.9 \pm 0.5$ & $9.4 \pm 0.4$ & $8.6 \mathrm{~cm}$ & $8.6 \mathrm{~cm}$ & $11.1 \mathrm{~cm}$ & $11 \mathrm{~cm}$ & $<0.001^{*}$ \\
\hline Fmt-fmt & $10.9 \pm 0.6$ & $10.4 \pm 0.7$ & $9.7 \mathrm{~cm}$ & $8.7 \mathrm{~cm}$ & $12.8 \mathrm{~cm}$ & $13.3 \mathrm{~cm}$ & $<0.001^{*}$ \\
\hline$Z Y B$ & $14.6 \pm 2.1$ & $13 \pm 1.4$ & $11.2 \mathrm{~cm}$ & $11.3 \mathrm{~cm}$ & $19.4 \mathrm{~cm}$ & $18.9 \mathrm{~cm}$ & $<0.001^{*}$ \\
\hline $\mathrm{OBH}$ & $3.9 \pm 0.3$ & $3.7 \pm 0.3$ & $3.3 \mathrm{~cm}$ & $3.1 \mathrm{~cm}$ & $4.7 \mathrm{~cm}$ & $4.8 \mathrm{~cm}$ & $<0.001^{*}$ \\
\hline OBB & $4.1 \pm 0.4$ & $3.9 \pm 0.3$ & $3.4 \mathrm{~cm}$ & $3.3 \mathrm{~cm}$ & $4.9 \mathrm{~cm}$ & $4.8 \mathrm{~cm}$ & $<0.001^{*}$ \\
\hline PAC & $12 \pm 1$ & $11.6 \pm 0.8$ & $9.5 \mathrm{~cm}$ & $9.9 \mathrm{~cm}$ & $16.7 \mathrm{~cm}$ & $14.3 \mathrm{~cm}$ & $0.007^{*}$ \\
\hline BMS & $10.5 \pm 0.6$ & $10 \pm 0.5$ & $8.7 \mathrm{~cm}$ & $8.5 \mathrm{~cm}$ & $12.4 \mathrm{~cm}$ & $10.9 \mathrm{~cm}$ & $<0.001^{*}$ \\
\hline $\mathrm{GOL}$ & $18.5 \pm 1$ & $17.8 \pm 0.8$ & $14.8 \mathrm{~cm}$ & $16.3 \mathrm{~cm}$ & $20.9 \mathrm{~cm}$ & $20.6 \mathrm{~cm}$ & $<0.001^{*}$ \\
\hline $\mathrm{BBH}$ & $13.9 \pm 0.7$ & $13.4 \pm 0.5$ & $11 \mathrm{~cm}$ & $11.8 \mathrm{~cm}$ & $15.1 \mathrm{~cm}$ & $14.8 \mathrm{~cm}$ & $<0.001^{*}$ \\
\hline BNL & $10.4 \pm 1.2$ & $10 \pm 0.6$ & $8 \mathrm{~cm}$ & $8.6 \mathrm{~cm}$ & $16.6 \mathrm{~cm}$ & $11.4 \mathrm{~cm}$ & $0.005^{*}$ \\
\hline $\mathrm{BPL}$ & $10.2 \pm 0.9$ & $9.7 \pm 0.5$ & $8.3 \mathrm{~cm}$ & $8.2 \mathrm{~cm}$ & $15 \mathrm{~cm}$ & $10.8 \mathrm{~cm}$ & $<0.001^{*}$ \\
\hline
\end{tabular}

All skull parameters and stature were measured in centimeter

$S D$ standard deviation, $X C B$ maximum cranial breadth, WFB minimum frontal breadth, fmt-fmt upper facial breadth, $Z Y B$ bizygomatic breadth, OBH orbital height, $O B B$ orbital breadth, $P A C$ parietal chord, $B M S$ bi-mastoidale, $G O L$ maximum cranial length, $B B H$ basion-bregma height, $B N L$ cranial base length, $B P L$ basion-prosthion length 
Table 4 Correlation between the stature and skull measurements in pooled cases $(n=150)$, males $(n=80)$, and females $(n=70)$ by Pearson's correlation coefficient

\begin{tabular}{|c|c|c|c|c|c|c|c|c|c|c|c|c|}
\hline & $X C B$ & WFB & Fmt-fmt & $Z Y B$ & $\mathrm{OBH}$ & OBB & PAC & BMS & $\mathrm{GOL}$ & $\mathrm{BBH}$ & $\mathrm{BNL}$ & $\mathrm{BPL}$ \\
\hline \multicolumn{13}{|c|}{ Pooled cases } \\
\hline$R$ & 0.519 & 0.384 & 0.345 & 0.555 & 0.382 & 0.394 & 0.268 & 0.373 & 0.497 & 0.348 & 0.221 & 0.376 \\
\hline$P$ value & $<0.001^{*}$ & $<0.001^{*}$ & $<0.001^{*}$ & $<0.001^{*}$ & $<0.001^{*}$ & $<0.001^{*}$ & $<0.001^{*}$ & $<0.001^{*}$ & $<0.001^{*}$ & $<0.001^{*}$ & $0.006^{*}$ & $<0.001^{*}$ \\
\hline \multicolumn{13}{|c|}{ In males } \\
\hline$R$ & 0.336 & 0.091 & 0.068 & 0.452 & 0.381 & 0.157 & 0.034 & 0.091 & 0.401 & 0.177 & 0.116 & 0.280 \\
\hline$P$ value & $0.002^{*}$ & 0.420 & 0.552 & $<0.001^{*}$ & $<0.001^{*}$ & 0.165 & 0.765 & 0.420 & $<0.001^{*}$ & 0.115 & 0.306 & $0.012^{*}$ \\
\hline \multicolumn{13}{|c|}{ In female } \\
\hline$R$ & 0.395 & 0.120 & 0.190 & 0.387 & 0.154 & 0.362 & 0.405 & 0.173 & 0.308 & 0.114 & 0.093 & 0.158 \\
\hline$P$ value & $0.001^{*}$ & 0.321 & 0.115 & $0.001^{*}$ & 0.204 & $0.002^{*}$ & $0.001^{*}$ & 0.151 & $0.010^{*}$ & 0.347 & 0.442 & 0.191 \\
\hline
\end{tabular}

$r$, correlation coefficient; weak $(R=0.20-0.39)$, moderate $(R=0.40-0.59)$, strong $(R=0.60-0.79)$, very strong $>0.8$

$X C B$ maximum cranial breadth, WFB minimum frontal breadth, fmt-fmt upper facial breadth, $Z Y B$ bizygomatic breadth, $O B H$ orbital height, $O B B$ orbital breadth, $P A C$ parietal chord, $B M S$ bi-mastoidale, $G O L$ maximum cranial length, $B B H$ basion-bregma, $B N L$ cranial base length, $B P L$ basion-prosthion length

*Significant difference, $P$ value $<0.05$

Table 5 Simple linear regression analysis to predict stature from skull measurements in pooled cases $(n=150)$

\begin{tabular}{|c|c|c|c|c|c|c|}
\hline \multirow[t]{2}{*}{ Measures } & \multicolumn{2}{|c|}{ Unstandardized coefficients } & \multirow[t]{2}{*}{$P$ value } & \multirow[t]{2}{*}{$R^{2}$} & \multirow[t]{2}{*}{ SEE $(\mathrm{cm})$} & \multirow[t]{2}{*}{ Regression equation } \\
\hline & $\bar{B}$ & Std. error & & & & \\
\hline$\overline{X C B}$ & 3.57 & 0.48 & $<0.001^{*}$ & 0.269 & 8.12 & $S=114.4+(3.57 \times X C B)$ \\
\hline Constant & 114.4 & 6.73 & $<0.001^{*}$ & & & \\
\hline WFB & 6.95 & 1.38 & $<0.001^{*}$ & 0.147 & 8.77 & $S=96.9+(6.95 \times W F B)$ \\
\hline Constant & 96.9 & 13.27 & $<0.001^{*}$ & & & \\
\hline Fmt-fmt & 4.57 & 1.02 & $<0.001^{*}$ & 0.119 & 8.92 & $S=115.2+(4.57 \times \mathrm{fmt}-\mathrm{fmt})$ \\
\hline Constant & 115.2 & 10.91 & $<0.001^{*}$ & & & \\
\hline ZYB & 2.7 & 0.33 & $<0.001^{*}$ & 0.308 & 7.9 & $S=126.5+(2.7 \times Z Y Y P)$ \\
\hline Constant & 126.5 & 4.64 & $<0.001^{*}$ & & & \\
\hline $\mathrm{OBH}$ & 11.18 & 2.22 & $<0.001^{*}$ & 0.146 & 8.78 & $S=121.1+(11.18 \times \mathrm{OBH})$ \\
\hline Constant & 121.1 & 8.51 & $<0.001^{*}$ & & & \\
\hline $\mathrm{OBB}$ & 11.07 & 2.12 & $<0.001^{*}$ & 0.155 & 8.73 & $S=119.6+(11.07 \times \mathrm{OBB})$ \\
\hline Constant & 119.6 & 8.5 & $<0.001^{*}$ & & & \\
\hline PAC & 2.8 & 0.83 & $0.001^{*}$ & 0.072 & 9.15 & $S=130.7+(2.8 \times P A C)$ \\
\hline Constant & 130.7 & 9.85 & $<0.001^{*}$ & & & \\
\hline BMS & 5.84 & 1.2 & $<0.001^{*}$ & 0.139 & 8.81 & $S=104+(5.84 \times \mathrm{BM})$ \\
\hline Constant & 104 & 12.28 & $<0.001^{*}$ & & & \\
\hline GOL & 4.85 & 0.7 & $<0.001^{*}$ & 0.247 & 8.24 & $S=75.7+(4.85 \times \mathrm{GOL})$ \\
\hline Constant & 75.7 & 12.67 & $<0.001^{*}$ & & & \\
\hline $\mathrm{BBH}$ & 4.83 & 1.07 & $<0.001^{*}$ & 0.121 & 8.91 & $S=98+(4.83 \times \mathrm{BBH})$ \\
\hline Constant & 98 & 14.61 & $<0.001^{*}$ & & & \\
\hline BNL & 2.05 & 0.74 & $0.006^{*}$ & 0.049 & 9.26 & $S=142.9+(2.05 \times \mathrm{BNL})$ \\
\hline Constant & 142.9 & 7.62 & $<0.001^{*}$ & & & \\
\hline BPL & 4.54 & 0.92 & $<0.001^{*}$ & 0.142 & 8.8 & $S=118.5+(4.54 \times B P L)$ \\
\hline Constant & 118.5 & 9.2 & $<0.001^{*}$ & & & \\
\hline
\end{tabular}

$R^{2}$, co-efficient determination; < 0.1 (trivial), 0.1-0.3 (small to medium), $0.3-0.5$ (medium to large), $>0.5$ (large to very large)

SEE standard error of estimate

*Significant level at $P$ value $<0.05$ 
Table 6 Simple linear regression analysis to predict stature from skull measurements in males $(\mathrm{N}=80)$

\begin{tabular}{|c|c|c|c|c|c|c|}
\hline \multirow{2}{*}{$\begin{array}{l}\text { Skull } \\
\text { measurements }\end{array}$} & \multicolumn{2}{|c|}{ Unstandardized coefficients } & \multirow[t]{2}{*}{$P$ value } & \multirow[t]{2}{*}{$R^{2}$} & \multirow[t]{2}{*}{ SEE $(\mathrm{cm})$} & \multirow[t]{2}{*}{ Regression equation } \\
\hline & $B$ & Std. error & & & & \\
\hline $\mathrm{XCB}$ & 1.54 & 0.49 & $<0.001^{*}$ & 0.113 & 6.03 & $S=[147.8+(1.54 \times X C B)]$ \\
\hline Constant & 147.8 & 7.07 & $<0.001^{*}$ & & & \\
\hline $\mathrm{ZYB}$ & 1.4 & 0.31 & $<0.001^{*}$ & 0.204 & 5.71 & $S=[149.5+(1.4 \times Z Y Y B)]$ \\
\hline Constant & 149.5 & 4.6 & $<0.001^{*}$ & & & \\
\hline $\mathrm{OBH}$ & 7.11 & 1.95 & $<0.001^{*}$ & 0.145 & 5.92 & $S=[142.2+(7.11 \times \mathrm{OBH})]$ \\
\hline Constant & 142.2 & 7.65 & $<0.001^{*}$ & & & \\
\hline GOL & 2.65 & 0.69 & $<0.001^{*}$ & 0.160 & 5.87 & $S=[120.9+(2.65 \times \mathrm{GOL})]$ \\
\hline Constant & 120.9 & 12.72 & $<0.001^{*}$ & & & \\
\hline $\mathrm{BPL}$ & 2 & 0.78 & $0.012^{*}$ & 0.078 & 6.15 & $S=[149.5+(2 \times B P L)] \pm 6.15$ \\
\hline Constant & 149.5 & 7.97 & $<0.001^{*}$ & & & \\
\hline
\end{tabular}

$\mathrm{R}^{2}$, co-efficient determination; < 0.1 (trivial), 0.1-0.3 (small to medium), 0.3-0.5 (medium to large), > 0.5 (large to very large)

SEE standard error of estimate

*Significant level at $P$ value $<0.05$

most predictable measurement was $\mathrm{ZYB}$ in pooled cases and in males only with the lowest SEE $7.9 \mathrm{~cm}$ and $5.71 \mathrm{~cm}$, respectively, while PAC was the most predictable and had the least $\operatorname{SEE}(6.86 \mathrm{~cm})$ in females.

The results of multiple linear regression equations were shown in Table 8 which showed less SEE values than simple linear regression equations in pooled cases, males and females.

Tables 9, 10, and 11 showed results of stepwise multiple linear regression analysis in pooled cases, males and females, respectively, which demonstrated nearly the same SEE values of multiple linear regression with less measurements used that is valuable especially in fragmented skull.

\section{Discussion}

Estimation of stature is one of the essential components in establishing identity in forensic anthropology as well as cranium is an important bone that has generated great interest among forensic anthropologists; furthermore, MDCT has generated valuable rule in forensic anthropology. So, this study aimed to stature estimation using cranial measurements in MDCT images.

The mean stature in this study was more in males $(169.9 \pm 6.4 \mathrm{~cm})$ in comparison with females $(156.9 \pm$ $7.5 \mathrm{~cm}$ ) which agrees with other studies done on $\mathrm{Su}$ danese by Ahmed and Taha (2016), Indian by Shrestha et al. (2015), and Japanese population by Torimitsu et al. (2016). However, the mean values of

Table 7 Simple linear regression analysis to predict stature from skull measurements in females $(n=70)$

\begin{tabular}{|c|c|c|c|c|c|c|}
\hline \multirow{2}{*}{$\begin{array}{l}\text { Skull } \\
\text { measurements }\end{array}$} & \multicolumn{2}{|c|}{ Unstandardized coefficients } & \multirow[t]{2}{*}{$P$ value } & \multirow[t]{2}{*}{$R^{2}$} & \multirow[t]{2}{*}{ SEE $(\mathrm{cm})$} & \multirow[t]{2}{*}{ Regression equation } \\
\hline & $B$ & Std. error & & & & \\
\hline$X C B$ & 2.7 & 0.76 & $0.001^{*}$ & 0.156 & 6.9 & $S=121.1+(2.7 \times X C B)$ \\
\hline Constant & 121.1 & 10.13 & $<0.001^{*}$ & & & \\
\hline ZYB & 2.06 & 0.6 & $0.001^{*}$ & 0.150 & 6.92 & $S=130.2+(2.06 \times Z Y P)$ \\
\hline Constant & 130.2 & 7.77 & $<0.001^{*}$ & & & \\
\hline OBB & 9.97 & 3.11 & $0.002^{*}$ & 0.131 & 7 & $S=118.3+(9.97 \times \mathrm{OBB})$ \\
\hline Constant & 118.3 & 12.08 & $<0.001^{*}$ & & & \\
\hline PAC & 3.74 & 1.03 & $0.001^{*}$ & 0.164 & 6.86 & $S=113.3+(3.74 \times P A C)$ \\
\hline Constant & 113.3 & 11.96 & $<0.001^{*}$ & & & \\
\hline $\mathrm{GOL}$ & 2.77 & 1.04 & $0.010^{*}$ & 0.095 & 7.14 & $S=107.6+(2.77 \times G O L)$ \\
\hline Constant & 107.6 & 18.5 & $<0.001^{*}$ & & & \\
\hline
\end{tabular}

$R^{2}$, co-efficient determination; < 0.1 (trivial), $0.1-0.3$ (small to medium), $0.3-0.5$ (medium to large), > 0.5 (large to very large) SEE standard error of estimate

* Significant level at $P$ value $<0.05$ 
Table 8 multiple linear regression analysis to predict stature from skull measurements in pooled cases $(n=150)$, males $(n=80)$, and females $(n=70)$

\begin{tabular}{llll}
\hline Subjects & Regression equations & $R_{\text {adj }}^{2}$ & SEE $(\mathrm{cm})$ \\
\hline Pooled cases & $S=[3.34+(1.32 \times \times C B)+(1.52 \times$ WFB $)+(0.05 \times$ fmt-fmt $)+(1.49 \times$ ZYB $)+(5.54 \times \mathrm{OBH})+(3.23 \times$ & 0.566 & 6.21 \\
& $\mathrm{OBB})+(0.89 \times \mathrm{PAC})+(1.76 \times \mathrm{BMS})+(0.49 \times \mathrm{GOL})+(0.91 \times \mathrm{BBH})+(-0.01 \times \mathrm{BNL})+(2.25 \times \mathrm{BPL})]$ & \\
Males & $\mathrm{S}=[10.28+(0.87 \times \mathrm{XCB})+(1.5 \times \mathrm{ZYB})+(5.52 \times \mathrm{OBH})+(0.85 \times \mathrm{GOL})+(2.26 \times \mathrm{BPL})]$ & 0.455 & 4.7 \\
Females & $\mathrm{S}=[71.9+(1.67 \times \mathrm{XCB})+(0.75 \times \mathrm{ZYB})+(7.37 \times \mathrm{OBB})+(1.93 \times \mathrm{PAC})+(0.12 \times \mathrm{GOL})]$ & 0.285 & 6.3 \\
\hline
\end{tabular}

$R_{\text {adj }}^{2}$ adjusted co-efficient determination; $<0.1$ (trivial), $0.1-0.3$ (small to medium), 0.3-0.5 (medium to large), $>0.5$ (large to very large)

SEE standard error of estimate

*Significant level at $P$ value $<0.05$

Egyptian stature were lower than those of Sudanese and slightly higher than that of Indian and Japanese populations. Also, the means of skull measurements were significantly higher in males than in females; this is supported by most studies done in different populations.

The rTEMs and $R$ values indicate that a technical error was likely to be accepted in this study which suggested that bone measurements using MDCT images can be performed without significant technical error; this coincides with Torimitsu et al. (2016).

The present findings indicate that stature and all skull measurements used are positively and significantly correlated in all Egyptian cases, but these results differed by sex. In males, XCB, ZYB, OBH, GOL, and BPL measurements showed significant correlation with stature and in females, XCB, ZYB, $\mathrm{OBB}, \mathrm{PAC}$, and GOL measurements had significant correlation with stature; the higher correlation coefficients were observed for pooled cases than for males or females may be attributed to the larger sample size (the sum of males and females). Acharya et al. (2017) studied 113 dry skulls of South Indian males and concluded that GOL had significant positive strong correlation and $\mathrm{XCB}$ had moderate correlation, while fmt-fmt and PAC had a fair correlation with stature. Torimitsu et al. (2016) who reviewed 228 MDCT images of the Japanese population found that there were significant positive correlations between stature and all the five measurements used in all subjects, among males, all cranial measurements except PAC were significantly correlated with stature. However, among females, only the ZYB and XCB measurements were significantly correlated with stature which disagrees with the present results. However, in Colombians, González-Colmenares et al. (2016) reported that the correlation coefficients were found to be low in males. Among females, the co-efficient of correlation was not found to be statistically significant for stature and cranial measurements; this may be attributed to the a decrease number of Colombian female samples used (16 dry skulls) which differ from these results.

Studies among Northwest Indian (Sahni et al. 2010) and Indo-Mauritian (Agnihotri et al. 2011) populations showed low correlations between stature and seven facial measurements $(r<0.270$ for males and $r<0.195$ for females) and 14 cephalo-facial measurements $(r<0.494$ for males and $<0.382$ for females), respectively. Therefore, the different cephalo-facial measurements used in different studies are not similar with regard to stature; they differ between the sexes and among different populations as genetic factors, environmental and nutritional factors affect the growth of the skull (Duren et al. 2013).

Regarding SEE of simple linear regression analysis reported in this study ranged from $7.9 \mathrm{~cm}$ to 9.26 $\mathrm{cm}, 5.71 \mathrm{~cm}$ to $6.15 \mathrm{~cm}$, and $6.86 \mathrm{~cm} \mathrm{to} 7.14 \mathrm{~cm}$ in pooled cases, males and females, consequently, The high SEE values noted for combined sex were probably due to increased variance in the sample, and these results were comparable with Torimitsu et al. (2016) who reported SEE values in Japanese ranged from $6.918 \mathrm{~cm}$ to $9.123 \mathrm{~cm}$ in pooled cases, $5.581 \mathrm{~cm}$ to $5.956 \mathrm{~cm}$ in males, and $6.451 \mathrm{~cm}$ to $7.142 \mathrm{~cm}$ in females. Also, Chiba and Terazawa (1998) who investigated Japanese dry skull at autopsy reported SEE values ranged from $7.95 \mathrm{~cm}$ to 8.59 in pooled cases and $6.96 \mathrm{~cm}$ to $7.12 \mathrm{~cm}$ and $6.71 \mathrm{~cm}$ to $6.97 \mathrm{~cm}$ in males and females consequently which coincides with these results. Shreshta et al. (2015) studied 200 skulls of Nepalese cadavers and reported a minimum SEE value with GOL, $7.437 \mathrm{~cm}$ in pooled cases, and $6.894 \mathrm{~cm}$ in males and in females; the least SEE was $5.692 \mathrm{~cm}$.

In Sudanese, Ahmed and Taha (2016) reported lower SEE values ranged from $5.745 \mathrm{~cm}$ to $6.028 \mathrm{~cm}$ and from $5.587 \mathrm{~cm}$ to $5.903 \mathrm{~cm}$ in males and in females, consequently.

Multiple studies investigated a sample of Indian male skulls percutaneously as Krishan (2008) and 
Table 9 Multiple stepwise linear regression analysis of skull measurements for stature estimation in pooled cases $(n=150)$

\begin{tabular}{|c|c|c|c|c|c|c|c|}
\hline \multirow[t]{2}{*}{ Model } & \multirow[t]{2}{*}{ Measures } & \multicolumn{2}{|c|}{ Unstandardized Coefficients } & \multirow[t]{2}{*}{$P$ value } & \multirow[t]{2}{*}{$R_{\text {adj }}^{2}$} & \multirow[t]{2}{*}{ SEE } & \multirow[t]{2}{*}{ Regression equation } \\
\hline & & B & Std. error & & & & \\
\hline \multirow[t]{2}{*}{1} & $\mathrm{ZYB}$ & 2.7 & 0.33 & $<0.001^{*}$ & \multirow[t]{2}{*}{0.304} & \multirow[t]{2}{*}{7.9} & \multirow[t]{2}{*}{$S=126.5+(2.7 \times Z Y Y B)$} \\
\hline & Constant & 126.5 & 4.64 & $<0.001^{*}$ & & & \\
\hline \multirow[t]{3}{*}{2} & $\mathrm{ZYB}$ & 2.03 & 0.33 & $<0.001^{*}$ & \multirow[t]{3}{*}{0.409} & \multirow[t]{3}{*}{7.3} & \multirow[t]{3}{*}{$S=101.8+(2.03 \times Z Y Y B)+(2.46 \times X C B)$} \\
\hline & $X C B$ & 2.46 & 0.47 & $<0.001^{*}$ & & & \\
\hline & Constant & 101.8 & 6.38 & $<0.001^{*}$ & & & \\
\hline \multirow[t]{4}{*}{3} & $\mathrm{ZYB}$ & 1.88 & 0.31 & $<0.001^{*}$ & \multirow[t]{4}{*}{0.484} & \multirow[t]{4}{*}{6.8} & \multirow{4}{*}{$\begin{array}{l}S=72.1+(1.88 \times Z \mathrm{ZYB})+(2.31 \times \mathrm{XCB}) \\
+(3.39 \times \mathrm{BPL})\end{array}$} \\
\hline & $X C B$ & 2.31 & 0.44 & $<0.001^{*}$ & & & \\
\hline & BPL & 3.39 & 0.72 & $<0.001^{*}$ & & & \\
\hline & Constant & 72.1 & 8.66 & $<0.001^{*}$ & & & \\
\hline \multirow[t]{5}{*}{4} & $\mathrm{ZYB}$ & 1.82 & 0.3 & $<0.001^{*}$ & \multirow[t]{5}{*}{0.428} & \multirow[t]{5}{*}{6.5} & \multirow{5}{*}{$\begin{array}{l}S=56.3+(1.82 \times \mathrm{ZYB})+(2.04 \times \mathrm{XCB}) \\
+(2.88 \times \mathrm{BPL})+(6.34 \times \mathrm{OBB})\end{array}$} \\
\hline & $X C B$ & 2.04 & 0.43 & $<0.001^{*}$ & & & \\
\hline & $\mathrm{BPL}$ & 2.88 & 0.7 & $<0.001^{*}$ & & & \\
\hline & OBB & 6.34 & 1.65 & $<0.001^{*}$ & & & \\
\hline & Constant & 56.3 & 9.25 & $<0.001^{*}$ & & & \\
\hline \multirow[t]{6}{*}{5} & $\mathrm{ZYB}$ & 1.8 & 0.29 & $<0.001^{*}$ & \multirow[t]{6}{*}{0.547} & \multirow[t]{6}{*}{6.4} & \multirow{6}{*}{$\begin{array}{l}S=47.5+(1.8 \times \mathrm{ZYB})+(1.78 \times \mathrm{XCB}) \\
+(2.79 \times \mathrm{BPL})+(5.25 \times \mathrm{OBB})+(4.69 \\
\times \mathrm{OBH})\end{array}$} \\
\hline & $X C B$ & 1.78 & 0.43 & $<0.001^{*}$ & & & \\
\hline & $\mathrm{BPL}$ & 2.79 & 0.69 & $<0.001^{*}$ & & & \\
\hline & OBB & 5.25 & 1.67 & $0.002^{*}$ & & & \\
\hline & $\mathrm{OBH}$ & 4.69 & 1.75 & $0.008^{*}$ & & & \\
\hline & Constant & 47.5 & 9.64 & $<0.001^{*}$ & & & \\
\hline \multirow[t]{7}{*}{6} & ZYB & 1.69 & 0.29 & $<0.001^{*}$ & \multirow[t]{7}{*}{0.562} & \multirow[t]{7}{*}{6.3} & \multirow{7}{*}{$\begin{array}{l}S=31.5+(1.69 \times \mathrm{ZYB})+(1.62 \times \mathrm{XCB}) \\
+(2.5 \times \mathrm{BPL})+(4.27 \times \mathrm{OBB})+(5.51 \times \\
\mathrm{OBH})+(2.29 \times \mathrm{BMS})\end{array}$} \\
\hline & $\mathrm{XCB}$ & 1.62 & 0.43 & $<0.001^{*}$ & & & \\
\hline & $\mathrm{BPL}$ & 2.5 & 0.69 & $<0.001^{*}$ & & & \\
\hline & OBB & 4.27 & 1.69 & $0.013^{*}$ & & & \\
\hline & $\mathrm{OBH}$ & 5.51 & 1.75 & $0.002^{*}$ & & & \\
\hline & BMS & 2.29 & 0.94 & $0.016^{*}$ & & & \\
\hline & Constant & 31.5 & 11.54 & $0.007^{*}$ & & & \\
\hline
\end{tabular}

$R_{\text {adj, }}^{2}$ adjusted co-efficient determination; $<0.1$ (trivial), 0.1-0.3 (small to medium), 0.3-0.5 (medium to large), $>0.5$ (large to very large)

*Significant level at $P$ value $<0.05$

Krishan and Kumar (2007) and revealed SEE values $3.726 \mathrm{~cm}$ to $5.820 \mathrm{~cm}, 4.41 \mathrm{~cm}$ to $7.21 \mathrm{~cm}$, consequently. Also, Patil and Mody (2005) used a lateral cephalogram of 150 adults from Central India and indicated that GOL can be used to estimate the stature; however, the SEE and $R$ values for their regression equations were not provided for comparison. The SEE values of Sahni et al. (2010) who studied facial measurements of 300 adults in Northwest India were much less than the values reported in this study, $3.56 \mathrm{~cm}$ to $3.70 \mathrm{~cm}$ in males and 2.90 to 2.95 in females.

The results of SEE of multiple linear regression analysis and stepwise regression analysis showed lower SEE values than simple linear regression analysis, $6.3 \mathrm{~cm}$ in pooled cases, $4.7 \mathrm{~cm}$ in males, and $6.3 \mathrm{~cm}$ in females; this goes in line with most studies mentioned above which concluded the same as illustrated in Table 12.

Genetics and environment may affect skeletal development; thus, when cephalometric measurements are used to determine sex or stature, it is necessary to develop specific formulae for each population (Vercellotti et al. 2009). The great result variability may be due to the difference in the measurements used in each study and techniques used for obtaining these measures in either MDCT, percutaneous, or dry bones. Although Franklin et al. (2013) stated that the precision of MDCT-derived measurements is high enough for the error to be negligible 
Table 10 Multiple stepwise linear regression analysis of skull measurements for stature estimation in males $(n=80)$

\begin{tabular}{|c|c|c|c|c|c|c|c|}
\hline \multirow[t]{2}{*}{ Model } & \multirow{2}{*}{$\begin{array}{l}\text { Measures } \\
\text { in males }\end{array}$} & \multicolumn{2}{|c|}{ Unstandardized coefficients } & \multirow[t]{2}{*}{$P$ value } & \multirow[t]{2}{*}{$R_{\text {adj }}^{2}$} & \multirow[t]{2}{*}{ SEE } & \multirow[t]{2}{*}{ Regression equation } \\
\hline & & B & Std. error & & & & \\
\hline \multirow[t]{2}{*}{1} & ZYB & 1.4 & 0.31 & $<0.001^{*}$ & 0.194 & 5.71 & $S=[149.5+(1.4 \times Z Y P)]$ \\
\hline & Constant & 149.5 & 4.6 & $<0.001^{*}$ & & & \\
\hline \multirow[t]{3}{*}{2} & ZYB & 1.35 & 0.29 & $<0.001^{*}$ & 0.318 & 5.26 & $S=[123.8+(1.35 \times Z Y P)+(6.77 \times O B H)]$ \\
\hline & $\mathrm{OBH}$ & 6.77 & 1.73 & $<0.001^{*}$ & & & \\
\hline & Constant & 123.8 & 7.84 & $<0.001^{*}$ & & & \\
\hline \multirow[t]{4}{*}{3} & ZYB & 1.43 & 0.27 & $<0.001^{*}$ & 0.399 & 4.93 & $S=[102.5+(1.43 \times Z Y P)+(6.42 \times O B H)+(2.11 \times B P L)]$ \\
\hline & $\mathrm{OBH}$ & 6.42 & 1.63 & $<0.001^{*}$ & & & \\
\hline & BPL & 2.11 & 0.63 & $0.001^{*}$ & & & \\
\hline & Constant & 102.5 & 9.7 & $<0.001^{*}$ & & & \\
\hline \multirow[t]{5}{*}{4} & ZYB & 1.3 & 0.27 & $<0.001^{*}$ & 0.440 & 4.76 & $S=[82.5+(1.3 \times \mathrm{ZYP})+(5.87 \times \mathrm{OBH})+(1.74 \times \mathrm{BPL})+(1.5 \times \mathrm{GOL})]$ \\
\hline & $\mathrm{OBH}$ & 5.87 & 1.59 & $<0.001^{*}$ & & & \\
\hline & $\mathrm{BPL}$ & 1.74 & 0.62 & $0.006^{*}$ & & & \\
\hline & $\mathrm{GOL}$ & 1.5 & 0.59 & $0.013^{*}$ & & & \\
\hline & Constant & 82.5 & 12.2 & $<0.001^{*}$ & & & \\
\hline
\end{tabular}

$R_{\text {adj, }}^{2}$ adjusted co-efficient determination; < 0.1 (trivial), 0.1-0.3 (small to medium), 0.3-0.5 (medium to large), $>0.5$ (large to very large)

SEE standard error of estimate

*Significant level at $P$ value $<0.05$

compared to the sample variance but also found that traditional bone measurements are more precise than their MDCT counterparts, so this point must be further investigated.

\section{Conclusion}

On the basis of simple regression equations developed from this study, it is concluded that bizygomatic breadth could be used for stature estimation in pooled cases and in males, while parietal chord in females and using multiple and multiple stepwise regression equations had lower SEE values. However $R^{2}$ values are too low which makes cranial MDCT images have limited utility; hence, these should be used a last resort and alternative method for stature estimation in Egyptians when more accurate skeletal elements such as intact long bones are not available for investigations.

The age groups used (21-60 years) are considered a limitation in this study as age groups less than the age of epiphyseal closure must be investigated to assess the reliability of using cranial MDCT for their

Table 11 Multiple stepwise linear regression analysis of skull measurements for stature estimation in females $(n=70)$

\begin{tabular}{|c|c|c|c|c|c|c|c|}
\hline \multirow[t]{2}{*}{ Model } & \multirow{2}{*}{$\begin{array}{l}\text { Measures in } \\
\text { females }\end{array}$} & \multicolumn{2}{|c|}{ Unstandardized Coefficients } & \multirow[t]{2}{*}{$P$ value } & \multirow[t]{2}{*}{$\mathrm{R}_{\text {adj }}^{2}$} & \multirow[t]{2}{*}{ SEE } & \multirow[t]{2}{*}{ Regression equation } \\
\hline & & B & Std. error & & & & \\
\hline \multirow[t]{2}{*}{1} & PAC & 3.74 & 1.03 & $0.001^{*}$ & \multirow[t]{2}{*}{0.152} & \multirow[t]{2}{*}{6.86} & \multirow[t]{2}{*}{$S=[113.3+(3.74 \times P A C)\}$} \\
\hline & Constant & 113.3 & 11.96 & $<0.001^{*}$ & & & \\
\hline \multirow[t]{3}{*}{2} & PAC & 3.26 & 0.99 & $0.002^{*}$ & \multirow[t]{3}{*}{0.229} & \multirow[t]{3}{*}{6.54} & \multirow[t]{3}{*}{$S=[87+(3.26 \times P A C)+(8.27 \times \mathrm{OBB})]$} \\
\hline & OBB & 8.27 & 2.96 & $0.007^{*}$ & & & \\
\hline & Constant & 87 & 14.79 & $<0.001^{*}$ & & & \\
\hline \multirow[t]{4}{*}{3} & PAC & 2.3 & 1.02 & $<0.001^{*}$ & \multirow[t]{4}{*}{0.290} & \multirow[t]{4}{*}{6.29} & \multirow{4}{*}{$\begin{array}{l}S=[72.59+(2.3 \times P A C)+(8.12 \times O B B) \\
+(1.94 \times X C B)]\end{array}$} \\
\hline & $\mathrm{OBB}$ & 8.12 & 2.84 & $0.027^{*}$ & & & \\
\hline & $X C B$ & 1.94 & 0.75 & $0.005^{*}$ & & & \\
\hline & Constant & 72.59 & 15.23 & $<0.001^{*}$ & & & \\
\hline
\end{tabular}

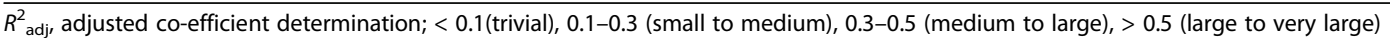
SEE standard error of estimate

*Significant difference at $P$ value $<0.05$ 
Table 12 demonstrating SEE in different studies among different population

\begin{tabular}{|c|c|c|c|c|c|}
\hline Study & Population & Method & Sex & SEE (simple) (cm) & SEE (multiple) (cm) \\
\hline Krishan and Kumar (2007) & North Indian & Percutaneous & Male & 4.41 & - \\
\hline Krishan (2008) & North Indian & Percutaneous & Male & 4.136 & - \\
\hline \multirow[t]{2}{*}{ Sahni et al. (2010) } & Northwest Indian & Percutaneous & & 3.56 & 3.569 \\
\hline & & & Male & 2.90 & 2.880 \\
\hline Acharya et al. (2017) & South India & Direct bone & Female & 4.90 & 4.45 \\
\hline \multirow[t]{3}{*}{ Shrestha et al. (2015) } & Nepalese & Direct bone & Male & 6.894 & 6.640 \\
\hline & & & Female & 5.692 & 5.538 \\
\hline & & & Pooled & 7.437 & 6.943 \\
\hline \multirow[t]{3}{*}{ Chiba and Terazawa (1998) } & Japanese & Direct bone & Male & 7.09 & 6.96 \\
\hline & & & Female & 6.59 & 6.71 \\
\hline & & & Pooled & 8.14 & 7.95 \\
\hline \multirow[t]{3}{*}{ Torimitsu et al. (2016) } & Japanese & 3D CT bone & Male & 5.581 & 5.406 \\
\hline & & & Female & 6.451 & 6.314 \\
\hline & & & Pooled & 6.918 & 6.394 \\
\hline \multirow[t]{3}{*}{ Ahmed and Taha (2016) } & Sudanese & Percutaneous & Male & 5.698 & 5.532 \\
\hline & & & Female & 5.587 & 5.253 \\
\hline & & & Pooled & - & - \\
\hline \multirow[t]{3}{*}{ The current study } & Egyptian & 3D CT bone & Male & 5.71 & 4.76 \\
\hline & & & Female & 6.86 & 6.3 \\
\hline & & & Pooled & 7.9 & 6.3 \\
\hline
\end{tabular}

stature estimation, and also, studying the effect of age on stature and skull measurements must be further investigated. Software programs for landmark location determination are not available. Another limitation that the regression equations developed from this study is untested for its validation; this point needs future consideration.

\section{Abbreviations}

BBH: Basion-bregma height; BMS: Bi-mastoidale; BNL: Cranial base length; BPL: Basion-prosthion length; fmt-fmt: Upper facial breadth; GOL: Maximum cranial length; MDCT: Multi-detector computed tomography; OBB: Orbital breadth; OBH: Orbital height; PAC: Parietal chord; SEE: Standard error of estimate; WFB: Minimum frontal breadth; XCB: Maximum cranial breadth; ZYB: Bizygomatic breadth

\section{Acknowledgements}

Many thanks to all workers in the radiology department, Minia University Hospital, and also, the authors thank Dr. Mostafa Mohamed Asem for the statistical analysis done.

\section{Authors' contributions}

$\mathrm{HA}$ and $\mathrm{OH}$ are responsible for the interpretation of results and for writing and final revision of the paper. RA and EG are responsible for obtaining the measures of the research. All authors read and approved the final manuscript.

\section{Funding}

No funding resources.

\section{Availability of data and materials}

The datasets supporting the conclusions of this article are included within the article.
Ethics approval and consent to participate

The Ethical Committee of the Faculty of Medicine, Minia University, approved this research.

\section{Consent for publication}

Not applicable.

\section{Competing interests}

The authors declare that they have no competing interest.

\section{Author details}

${ }^{1}$ Forensic Medicine and Toxicology Department, Faculty of Medicine, Minia University, Minya, Egypt. ${ }^{2}$ Radiology Department, Faculty of Medicine, Minia University, Minya, Egypt.

Received: 13 May 2019 Accepted: 2 October 2019

Published online: 25 November 2019

\section{References}

Acharya J, Shetty BSK, Shrestha R, Kanchan T (2017) Approximation of height of an individual using somatometry of human male skull. J Nepal Med Assoc 56(206):238-242

Agnihotri AK, Kachhwaha S, Googoolye K, Allock A (2011) Estimation of stature from cephalo-facial dimensions by regression analysis in Indo-Mauritian population. J. Forensic Leg Med 18:167-172

Ahmed AA, Taha S (2016) Cephalo-facial analysis to estimate stature in a Sudanese population. Legal Medicine 20:80-86

Chiba M, Terazawa K (1998) Estimation of stature from somatometry of skull. Forensic Sci Int 97:87-92

Cline MG, Meredith KE, Boyer JT, Burrows B (1989) Decline of height with age in adults in a general population sample: estimating maximum height and distinguishing birth cohort effects from actual loss of stature with aging. Human Biology 61(3):415-425

Dayal MR, Steyn M, Kuykendall KL (2008) Stature estimation from bones of South African whites. S Afr J Sci 104:124-128 
Divakar DD, John J, Alkhuraif A, Alshahra OA (2015) Cranio-mandibular parameters of lateral cephalometric radiograph to determine sex in forensic investigations: an electronic search study. Anthropologist 21(1-2):98-104

Duren DL, Seselj M, Froehle AW, Nahhas RW, Sherwood RJ (2013) Skeletal growth and the changing genetic landscape during childhood and adulthood. Am J Phys Anthropol 150:48-57

Duyar I, Pelin C (2003) Body height estimation based on tibia length in different stature groups. Am J Phys Anthropol 122:23-27

Franklin D, Cardini A, Flavel A, Kuliukas A, Marks MK, Hart R et al (2013) Concordance of traditional osteometric and volume-rendered MSCT interlandmark cranial measurements. Int J Legal Med 127:505-520

Franklin D, Swift L, Flavel A (2016) Virtual anthropology and radiographic imaging in the Forensic Medical Sciences. Egyptian Journal of Forensic Sciences 6(2): $31-43$

González-Colmenares G, Medina CS, Báez LC (2016) Estimation of stature by cephalometric facial dimensions in skeletonized bodies: study from sample modern Colombians skeletal remains. Forensic Science International 258:101. e1-101.e6

Howells WW (1989) Skull shapes and the map: craniometric analyses in the dispersion of modern Homo. Pap Peabody Museum Archaeol Ethnol 79

Jamaiyah H, Geeta A, Safiza MN, Khor GL, Wong NF, Kee CC et al (2010) Reliability, technical error of measurements and validity of length and weight measurements for children under two years old in Malaysia. Med. J Malaysia 65:131-137

Kanchan T, Kumar GP, Menezes RG (2008) Index and ring finger ratio: a new sex determinant in the South-Indian population. Forensic Sci Int 181:53e1-53e4

Krishan K (2008) Estimation of stature from cephalo-facial anthropometry in North Indian population. Forensic Sci Int 181(52):e1-e6

Krishan K, Kanchan T, Menezes RG, Ghosh A (2012) Forensic anthropology casework-essential methodological considerations in stature estimation. J Forensic Nurs 8(1):45-50

Krishan K, Kumar R (2007) Determination of stature from cephalo-facial dimensions in a North Indian population. Legal Medicine 9:128-133

Kumar S, Gatg R, Mogra K, Choudhary R (2013) Prediction of stature by the measurement of head length in population of Rajasthan. J Evol Med Dent Sci 14:1334-1339

Moore-Jansen PH, Ousley SD, Jantz RL (1994) Data collection procedures for forensic skeletal material, Report of Investigations No. 48, Department of Anthropology, University of Tennessee, Knoxville.

Numan Al, Idris MO, Zirahei JV, Amaza DS, Dalori MB (2013) Prediction of stature from hand anthropometry: a comparative study in the three major ethnic groups in Nigeria. British Journal of Medicine \& Medical Research 3(4):10621073

Patila KR, Mody RN (2005) Determination of sex by discriminant function analysis and stature by regression analysis: a lateral cephalometric study. Forensic Science International 147:175-180

Raxter MH, Auerbach B, Ruff CB (2006) Revision of the fully technique for estimating statures. Am J Phys Anthropol 30:374-384

Sahni D, Sanjeev SP, Harjeet KG, Aggarwal A (2010) Estimation of stature from facial measurements in northwest Indians. Legal Medicine 12:23-27

Scheuer L, Black S (2004) Juvenile skeletal remains: provenance, identification and interpretation. In: The Juvenile Skeleton. Academic Press, London, pp 10-32

Shrestha R, Shrestha PK, Wasti H, Kadel T, Kanchan T, Krishan K (2015) Craniometric analysis for estimation of stature in Nepalese population - a study on an autopsy sample. Forensic Sci Int 248(187):e1-e6

Torimitsu S, Makino Y, Saitoh H, Sakuma A, Ishii N, Yajima D et al (2016) Stature estimation from skull measurements using multidetector computed tomographic images: a Japanese forensic sample. Legal Medicine 18:75-80 Vercellotti G, Agnew AM, Justus HM, Sciulli PW (2009) Stature estimation in an early medieval (XI-XII c.) Polish population: testing the accuracy of regression equations in a bioarcheological sample. Am J Phys Anthropol 140:135-114

\section{Publisher's Note}

Springer Nature remains neutral with regard to jurisdictional claims in published maps and institutional affiliations.

\section{Submit your manuscript to a SpringerOpen ${ }^{\odot}$ journal and benefit from:}

- Convenient online submission

- Rigorous peer review

- Open access: articles freely available online

- High visibility within the field

- Retaining the copyright to your article

Submit your next manuscript at $\boldsymbol{\nabla}$ springeropen.com 